\title{
Notas sobre um itinerário bibliográfico: onde estão os homossexuais negros?
}

\author{
Joilson Santana Marques Júnior*
}

Resumo: O presente artigo tem como objetivo apresentar resultados da investigação realizada, inicialmente, a partir de revisão bibliográfica acerca da questão racial e da homossexualidade. A experiência singular da homossexualidade negra, deslocada do lugar reservado à identidade negra ou identidade gay, produz contextos diferenciados de preconceitos e discriminação. Assim, a partir da seleção de uma bibliografia de referência na discussão da homossexualidade, procura-se mapear algumas questões: se há identificação de homossexuais negros; como eles aparecem nos textos e se, em algum momento, tornam-se eixo central de análise. Como resultado preliminar, concluise que, em um primeiro momento, esses sujeitos são identificados racialmente, até porque são os negros e mestiços os alvos de estudos de base antropo-criminológica. Mas, com o incremento de pesquisas menos discriminatórias que revelam a legitimidade desse desejo, posteriormente, os sujeitos das investigações e estudos tornam-se brancos.

Palavras-chave: Homossexualidade; raça; interseccionalidade.

\begin{abstract}
This article aims a brief investigation on the issue of race and homosexuality. The unique experience of black homosexuality moved from the place reserved for black identity and gay identity produces different contexts of prejudice and discrimination. Thus, from the selection of a bibliography of reference for the discussion of homosexuality, I try to map: If there is identification of gay black, as they appear in the text and if at any time become the central axis of analysis. As preliminary results we conclude that at first these guys are identified racially, because blacks and mestizos are the targets of basic anthropological studies and criminology. But with the increase of research reveals that less discriminatory the legitimacy of the subjects will become white.
\end{abstract}

Keywords: Homosexuality; race; intersectionality.

\footnotetext{
* Assistente social do Centro de Referência e Promoção da Cidadania LGBT Metropolitano vinculado à Superintendência de Direitos Individuais, Coletivos e Difusos (SUPERDIR) da Secretaria Estadual de Assistência Social e Direitos Humanos (SEASDH) do Rio de Janeiro e Mestre em Ciências na área da Saúde Coletiva (IFF/FIOCRUZ). E-mail: joutromundo2000@yahoo.com.br
} 


\section{ReVistg all pgutg}

\} NOTAS SOBRE UM ITINERÁRIO BIBLIOGRÁFICO - MARQUES JR., J. S. \}

\section{Introdução}

Este artigo parte de um estudo inicial que pretende realizar uma breve análise sobre a produção teórica acerca da identidade negra LGBT (Lésbica, Gay, Bissexual, Travesti e Transsexual) ou, antes, da homossexualidade negra e dos gays negros, já que em grande parte essas biografias versaram, ainda que de forma vaga, sobre esses sujeitos.

A princípio essa temática está relacionada com a trajetória do autor e com a sua visão de mundo, pois foi o pertencimento étnico/racial e a orientação sexual que, em um primeiro momento, levaram-no à militância e o conduziram aos caminhos de uma pesquisa acadêmica socialmente comprometida.

$\mathrm{O}$ artigo pretende mapear a existência da interseção entre "raça"1 e homossexualidade, em algumas referências bibliográficas que são utilizadas para os estudos sobre homossexualidade. De forma mais específica, se volta à investigação de como figuram os homossexuais negros nessa literatura.

Este artigo está dividido em duas seções: na primeira, são expostas as questões referentes à discussão da construção da interseccionalidade entre identidade negra e diversidade sexual e de gênero, de modo a demonstrar a relação existente entre sexismo, racismo e homofobia. De forma adicional, procura-se evidenciar também como essas construções se articulam para gerar opressões.

A segunda seção trata de uma revisão bibliográfica de alguns textos de referência para a discussão de homossexualidade e que, de alguma maneira, tangenciam ou têm como tema principal a homossexualidade negra a fim de mapear "se" e "como" tem emergido a relação entre essa produção teórica e os sujeitos negros homossexuais.

\section{Questão racial e homossexualidade: onde nos encontramos?}

O processo de construção do movimento pelo direito à diversidade sexual contemporâneo tem como marco inicial a noite da Rebelião de Stonewall², que deu início à construção de uma nova identidade para homossexuais através da identidade gay ${ }^{3}$.

No Brasil, o movimento toma corpo no final dos anos de 1970, mais precisamente quando é fundado o jornal Lampião da Esquina e o Grupo Somos ${ }^{5}$. Po-

\footnotetext{
1 A categoria "raça" biologicamente não existe. Neste artigo ela será utilizada por entendê-la enquanto conceito social que hierarquiza e estratifica seres humanos. É preciso situar esse conceito como apenas de análise social, pois, segundo Guimarães, "(...) as raças são cientificamente uma construção social" (2003, p.95).

${ }^{2}$ Stonewall era um bar que sofria constantes perseguições devido ao seu público "gay". Na noite de 28 de junho de 1969, a polícia mais uma vez realizou uma intervenção no local, porém, naquele dia, os frequentadores reagiram e resistiram à repressão policial. Abriu-se um conflito que durou cerca de dois dias entre gays e policiais. Um mês depois, a Frente de Libertação Gay (Instituição norte-americana de defesa dos direitos homossexuais) divulgou essa data como dia do orgulho gay (FRY e MACRAE, 1985, p.96-97)

${ }^{3}$ Segundo Lima, "a categoria 'gay' se dissemina no Brasil a partir da década de 70, do século XX. Originária do inglês norte-americano, quer dizer alegre feliz e supõe uma identidade social que se coadune com essa idéia. Essa identidade prevê uma relação sexual e afetiva igualitária entre os parceiros, a ideia do casal feliz, bem ajustado socialmente, tal como os modernos casais heterossexuais. Tende a condenar ou vê com maus olhos o sexo promíscuo ou o sexo perigoso com prostitutos e pessoas de classe, raça e etnia inferiorizadas" (2006, p.4-5).

${ }^{4} \mathrm{Em} \mathrm{1978,} \mathrm{foi} \mathrm{lançado} \mathrm{o} \mathrm{jornal} \mathrm{O} \mathrm{Lampião} \mathrm{da} \mathrm{Esquina} \mathrm{que} \mathrm{reunia} \mathrm{um} \mathrm{grupo} \mathrm{de} \mathrm{intelectuais,} \mathrm{artistas} \mathrm{etc.,} \mathrm{que} \mathrm{pro-}$ punham a positivação da homossexualidade e a articulação com outras populações historicamente discriminadas, a fim de promover o combate às discriminações (FRY e MACRAE, 1985;CARRARA et al,2010).

${ }^{5}$ Em 1979, nasce o SOMOS - Grupo de Afirmação Homossexual - com o objetivo de questionar as hierarquias baseadas no sexismo, buscando colocar na cena política a questão homossexualidade (FRY e MACRAE, 1985; CARRARA et al, 2010).
} 


\section{Revistg all paUtg}

\} NOTAS SOBRE UM ITINERÁRIO BIBLIOGRÁFICO - MARQUES JR., J. S. \}

rém, desde o início, o movimento gay tem se organizado em torno de uma identidade que referencia homens brancos de classe média (GOSINE, 2008).

Fry e MacRae (1985) atentam para o fato de que, mesmo o movimento gay representando um avanço na luta por direitos, ele se constituía com regras impostas "de fora para dentro". E ainda, assumia frequentemente posições opressoras a partir do estabelecimento de padrões estéticos e de consumo, que deixam de fora os não brancos, os sujeitos pertencentes às classes populares, entre outros. Embora não seja possível afirmar que o movimento gay é racista, não se pode furtar ao fato de que tais práticas perpassam sua construção.

É fato que a partir do ano 2000, essa discussão começa a tomar maior espaço. Em 2001, durante a preparação para a III Conferência Mundial de Combate ao Racismo, a Xenofobia e intolerâncias correlatas, em Durban, África do Sul. Foi organizado um encontro sobre racismo, discriminação e intolerância à diversidade sexual, além do fato de, na própria Conferência, ter sido organizado um painel sobre racismo e homofobia (BLACKWELL; NABER, 2002). Desde aquele momento tem se dado a construção de grupos políticos específicos para negros LGBTs e a criação de núcleos dentro dos grupos já existentes para discutir a questão dos "Afro-LGBTs".

A partir desse cenário, é possível questionar: como ocorrem as interlocuções entre essas categorias? Vistos de modo separado, racismo, machismo e sexismo não parecem se relacionar diretamente, mas quando se pensa em como esses "ismos" se articulam, formando os pilares de sustentação da cadeia de opressões constituídas, a partir de uma sociedade que se organiza através da reprodução de desigualdades, percebe-se que não é possível separar essas variáveis, pois elas atuam de forma interseccional. A partir dessa percepção, é possível começar um diálogo acerca da sexualidade atribuída aos negros ou, antes, da hipersexualização dos negros.

A construção da sexualidade do homem e da mulher negra perpassa a concepção de animalidade distante do humano, olhando mais especificamente para o homem negro nas palavras de Fanon (1983). É possível perguntar qual deve ser a conduta do homem negro em relação a sua sexualidade? O que se espera do negro?

Acredita-se que, em primeiro lugar, espera-se um animal sexual cujos impulsos e instintos dominam as ações. O mais interessante nessa característica atribuída aos negros é a sua positivação. Na verdade, a extrema virilidade atribuída ao negro é colocada como algo "positivo". De acordo com o imaginário social esse é o homem negro, todo o seu corpo e movimentos simbolizam o ato sexual e está é a sua única "qualidade" (ROSA, 2006; SOUZA, 2009).

Embora não se pretenda aprofundar nesse momento as consequências que isso traz para homens negros heterossexuais, é necessário colocar que uma das consequências da incorporação deste estereótipo é o impacto sobre o cuidado em saúde para esses homens (SOUZA, 2009).

Mas a pergunta que se explicita é: quando o homem negro trai a sua principal e, provavelmente, única qualidade positivada socialmente, isto é, como é viver sobre a identidade de negro gay? Utilizam-se aqui trechos de entrevista concedida à revista Raça, na qual é possível se aproximar do significado dessa experiência. Por exemplo, segundo Vinicius Matthews Rezende: “(...) pelo menos umas cinco vezes por semana ouço frases do tipo 'vira homem seu preto do caramba!' ou 'honre a sua 


\section{heVistg all pgutg}

\} NOTAS SOBRE UM ITINERÁRIO BIBLIOGRÁFICO - MARQUES JR., J. S. \}

cor!'”. Na mesma revista, outro entrevistado coloca: "ao sair na rua, ouço muitos e muitos por aí dizendo que estou sujando a cor, a raça" (FONSECA,2012,p.3).

Observa-se, assim, que para além da traição da masculinidade heterossexual, é uma traição à qualidade mais bem positivada do homem negro: a sua possante virilidade, seu incansável instinto sexual.

A partir do exposto, pode-se depreender que a vivência da homossexualidade negra é diferenciada, pois se vê recortada por uma identidade negra. No entanto, mais que representar uma soma de preconceitos, singulariza-se a construção de uma identidade que experiencia o fato de ser negro e gay, pois se a construção da sexualidade do homem negro obedece a outras regras, a construção da identidade negra homossexual também será diferenciada.

A partir dessa exposição, é possível travar um diálogo sobre a não homossexualidade negra, pois o seu deslocamento se dá tanto em relação à heterossexualidade hegemônica, quanto ao seu papel enquanto negro. Ao mesmo tempo, o gay negro, aos poucos, vai percebendo que o interior da comunidade homossexual é perpassado por preconceitos e estereótipos relacionados ao seu corpo e a sua sexualidade que o distanciam do ideário do ser gay. Nas palavras de Pinho:

A cena homossexual parecerá a alguns mais tolerantes ou aberta em termos de raça e classe (...) Entretanto, a convivência de homens gays de classes, raças, posições sociais e mesmo estilos diferentes significa igualdade ou simetria? Não podemos recair aqui no erro já superado pela sociologia das relações raciais, que a princípio não entendia que proximidade ou mesmo intimidade não significa ausência de dominação e violência, pelo contrário, a constituía. (2004, p.95).

Em outras palavras, o fato de negros e brancos gays ocuparem os mesmos espaços não significa que não haja racismo e, tampouco, que as desigualdades não se farão presentes. Dessa forma, quando se menciona o "não lugar", refere-se a esses aspectos, que tornam o negro gay um traidor de sua "raça", pois, parte-se do principio da relação homoerótica como sendo uma prerrogativa do homem branco. Assim, ele macula sua negritude simbolizada pela potência sexual e, para pessoas racistas e sexistas, ele "além de preto é viado". Mesmo para muitos gays brancos, ele é ora "mais um negro", ora um objeto do desejo exótico, e todo o fetiche do corpo negro vêm à tona.

Essa breve contextualização permite propor a perspectiva do direito à diversidade sexual para aqueles que pertencem à diversidade étnico-racial e viceversa. Isto é, preconiza-se o direito à diversidade dentro da diversidade.

Um primeiro passo, na luta pela garantia de direitos a essa população parece ter sido dado com a construção do "Programa Brasil Sem Homofobia" ${ }^{\text {, }}$ que tem um

\footnotetext{
${ }^{6}$ O Programa de Combate à Violência e à Discriminação contra GLBT e de Promoção da cidadania Homossexual, conhecido de forma geral como Programa Brasil Sem Homofobia, é uma diretriz que elenca uma série de estratégias e ações que visam ao combate à homofobia, ao acesso a direitos e à equiparação, em termos de cidadania, entre homossexuais e heterossexuais. (MINISTERIO DA SAÚDE, 2008).
} 


\section{hevistg em PaUtg}

\} NOTAS SOBRE UM ITINERÁRIO BIBLIOGRÁFICO - MARQUES JR., J. S. \}

eixo que trata das políticas de combate ao racismo e à homofobia. A princípio, é o item 48 do Programa de Ações do Brasil Sem Homofobia que visa criar uma estratégia de combate ao racismo e a homofobia, assim deve-se ressaltar que este foi um avanço em termos de construção de programas sociais numa perspectiva interseccional, pois trouxe para o interior do programa a discussão da diversidade sexual e do racismo combinados.

A partir dessas perspectivas, verifica-se a importância de uma reflexão sobre a construção de políticas públicas que rompam a fragmentação de identidades e percebam os atravessamentos que compõem a construção dos sujeitos, enfrentando assim o binarismo e a dicotomia presentes numa ótica de particionamento dos sujeitos, pois como sugere Ratts (2007:113): "o campo afro LGTTB me parece aberto às pessoas que não se afirmam e não se pautam por uma só identidade racial e afetivo-sexual".

\section{A produção bibliográfica e a homossexualidade negra}

O primeiro romance a ter como tema central uma relação homoerótica no Brasil chama-se O bom crioulo (CAMINHA, 1991 [1894]) e se desenvolve entre um negro e um branco, ambos pertencentes às classes populares. Este livro registra não só práticas sexuais, mas também um relacionamento, ainda que reproduzindo alguns estereótipos atribuídos aos negros, como, por exemplo, o papel de "ativo sexual".

Fry (1982) retoma o romance de Caminha (1894) para realizar uma análise acerca do mesmo, trazendo para o corpo de sua análise o fato de se tratar de uma relação homoerótica e com um dos personagens negro. É importante destacar que esse texto trata da análise de relações homoeróticas em dois romances naturalistas, não sendo, portanto, uma pesquisa sobre relações raciais e homossexualidade.

$\mathrm{O}$ autor conclui que em alguns momentos o romance se aproxima dos preconceitos da época, mas ao final tanto a questão racial quanto a relação entre dois homens é vista de forma mais simpática. Segundo o autor, houve um rompimento com a norma social da época, pois "a moral da história de Caminha, afinal, não é que os 'pederastas' são degenerados nem que os negros são incapazes de gozar a igualdade junto com os brancos" (FRY, 1982, p.49). É, no entender do autor, o assassinato do personagem que estaria no lugar do feminino, pelo masculino, que simboliza a manutenção dos padrões sociais em que o feminino que trai, merece a morte.

Há alguns outros aspectos no romance que merecem atenção: Amaro, o personagem negro, que se constitui como o "ativo" e "másculo" da relação, e isso, em verdade, se aproxima de um quadro já estabelecido para os homens negros no que se refere à sexualidade: o "ativo sexual/reprodutor" que impregna o imaginário. A proximidade entre a sexualidade atribuída aos negros e a animalidade tornou-se uma das características mais bem positivadas em relação ao homem negro. Outro ponto diz respeito ao fato de Aleixo (homem branco) não aparentar os mesmos sentimentos atribuídos a Amaro. É Amaro que não resiste aos impulsos da natureza.

A relação amorosa entre Aleixo e dona Carolina (a outra ponta do triângulo amoroso) poderia ser vista como a redenção de seu personagem que, diferentemente de Amaro, não é "escravo de sua natureza". E, por fim, o desfecho do romance não poderia ser outro, a "desgraça". Seria possível arriscar que quando o autor propõe 


\section{heVistg all pgutg}

\} NOTAS SOBRE UM ITINERÁRIO BIBLIOGRÁFICO - MARQUES JR., J. S. \}

esse final está transmitindo uma ideia de que essas relações, por mais que aparentem "normalidade", não podem ter outro final.

Por que Aleixo não trai Amaro com outro homem e sim com uma mulher? É possível inferir que, ao final, a sensação é de que essa relação não pode dar certo, pois na realidade ela não é "normal". Isto é, o final, para quem se entrega aos desejos "antinaturais", é ser assassino. Já para o que se entrega por interesses de outra ordem, o final é a morte. E o assassino - aquele que não refreia os seus impulsos é o personagem negro. Ou seja, embora seja possível concordar com Fry (1982), que este é um romance com visões contraditórias sobre "raça" e homossexualidade, acredita-se também que há outras possíveis leituras sobre essas questões e a forma como elas se relacionam no livro.

Green (2000), no capítulo denominado "Controle e cura: reações médicolegais", buscava analisar as medidas tomadas em relação ao controle e à cura de homossexuais a partir da década de 1930 no Brasil. Destaca-se que o autor, todavia, não se deteve ou teve como tema central de sua análise os homossexuais negros, mas observa-se que o referido capitulo é, entretanto, permeado pela discussão racial. Isso porque a análise do autor está centrada na revisão crítica das teorias e práticas que balizaram as ações interventivas junto aos homossexuais da época. Por conseguinte, o debate do autor girou em torno das teses higienistas e eugenistas dos anos de 1930. Neste sentido, segundo Green:

Lombroso (1836-1909), um dos pioneiros na antropologia criminal, defendia a teoria do delinquente nato (grifo do autor), cujo fragilizado sistema nervoso o predispunha a um comportamento degenerado, que incluía propensão à mutilação, tortura, homossexualidade e a fazer tatuagens pelo corpo. Lombroso e seus seguidores procuravam determinar a degeneração criminosa por meio de características fenotípicas (2000, p. 199).

Embora não seja estabelecida uma relação direta entre homossexualidade e raça, o trecho acima deixa clara a possível relação entre ambas. O estudo de Leonídio, também citado pelo autor, por exemplo, reúne, em sua maioria, o homossexual negro e o mestiço.

Green (2000) segue abrindo um tópico específico para tratar da relação "raça", homossexualidade e crime. Nele, o autor relata que, embora não tenha sido afirmada uma relação direta entre "raça" e homossexualidade, havia uma ênfase em afirmar negros e mestiços como pervertidos, como agentes que poriam em risco o "bom" desenvolvimento das classes médias brasileiras. Inclusive, as medidas de controle em relação aos homossexuais tinham uma bifurcação racial. Assim, "indivíduos de classes mais baixas e com tez mais escura eram mais vulneráveis a detenção por vadiagem e prostituição ou à acusação de atentado ao pudor do que os homossexuais de classe média. Estes sofriam uma forma diferente de controle social". (GREEN, 2000, p. 221).

Ao abordar a homossexualidade de negros e mestiços e a relação estabelecida pelos cientistas naquele momento entre raça e perversão, percebe-se que, no período 


\section{hevistg eIII pautg}

\} NOTAS SOBRE UM ITINERÁRIO BIBLIOGRÁFICO - MARQUES JR., J. S. \}

estudado, a homossexualidade estabelece um nexo com negros e mestiços, ainda que atado pelos laços da concepção de "degeneração racial"7.

Figari (2007) realizou uma pesquisa histórica sobre a homossexualidade no final do século XIX e início do século XX. No quarto capítulo da obra, o autor menciona a questão racial em alguns trechos, demonstrando como teses eugênicas articulavam raça e inversão. O autor revela que a condição de "invertido" para a ciência da época se relacionava com a sexualidade negra considerada como direcionada para a perversão e aos instintos animalescos:

Em um contexto de exaltação da raça e prevalência das teorias eugênicas nas ciências, sobretudo médicas, a sífilis, as enfermidades venéreas e as inúmeras desordens morais e sexuais eram atributos também dos(as) negros(as), construindo, assim, a representação de seu temperamento absolutamente libidinoso e lúbrico, desconhecedores de pudor e de castidade (2007).

As análises de Green (2000) e Figari (2007) se detiveram em um período histórico que vai do fim do século XIX aos primeiros anos do século XX. Tomando estas obras como exemplos e reconhecendo que embora não haja uma teoria constituída acerca da homossexualidade, percebe-se que a negritude/miscigenação foi relacionada a ela em diversos momentos, alinhavada pela verve da degeneração racial.

\section{Landes e Fry - Cultos afro-brasileiros e homossexuais negros: alguma coisa em comum?}

Ruth Landes publicou em 1947 (2002) o livro A cidade das mulheres, que centra sua pesquisa na análise dos cultos afro-brasileiros na Bahia e na liderança feminina em tais cultos, no final dos anos 1930. Em um artigo anexo intitulado "Matriarcado cultural e homossexualidade masculina", a autora expõe um fenômeno naquele momento considerado novo: o aparecimento de pais de santo homossexuais.

É naquele contexto que aparece a figura do homossexual negro e mestiço e - apesar de não ser o tema principal de seu trabalho -, ao abordar a homossexualidade masculina presente em cultos de caboclo, a autora nos traz o dado racial desses sujeitos. $\mathrm{O}$ artigo centra sua análise nas questões relacionadas à homossexualidade "passiva" e à expressão desta nos cultos e à ascensão dos indivíduos associados a tal prática como "pais de santo".

A autora cita que a origem desses homossexuais passivos era, em sua maioria, as ruas, e que eles eram negros. A autora não problematiza essa condição ou discute o porquê de todos serem negros e terem vindo frequentemente da prostituição. Não

\footnotetext{
${ }^{7} \mathrm{Em} 1768$, foi adicionada a esse corpus teórico a noção de degeneração. Isso ocorreu com as publicações do jurista Cornelius de Pauw que deu novas nuances a esse conceito. Inicialmente o conceito de degeneração era utilizado para classificar espécies inferiores por sua complexidade orgânica, esse autor por sua vez é um dos pioneiros em aplicar essa terminologia a grupos humanos e, ao mesmo tempo, em redefini-lo como um desvio patológico do modelo original. Sua visão associou à patologia as diferenças existentes entre os seres humanos e se constitui em consonância com uma profunda estratificação, a partir do pensamento europeu. Dentro da lógica desse autor, o tipo original era o europeu e as demais "espécies humanas" eram tipos desviantes, enfraquecidos ( $\mathrm{SCH}$ WARCZ, 1993).
} 


\section{ReVistg all pgutg}

\} NOTAS SOBRE UM ITINERÁRIO BIBLIOGRÁFICO - MARQUES JR., J. S. \}

foi o objetivo central dela problematizar esses ponto, mas, ainda assim, é transmitida uma visão acerca dos homossexuais passivos negros como sujeitos que se aproveitam do culto religioso para obterem vantagens e viverem sua feminilidade.

Fry (1982) coloca em debate a questão da homossexualidade e sua presença nos cultos afro-brasileiros, propondo uma revisão dos trabalhos que discutiram o assunto e pretende comprovar que, para além de um espaço onde homossexuais passivos poderiam se expressar de forma feminina, esse seria um espaço procurado por esses indivíduos, pois:

Primeiro, tanto a homossexualidade masculina quanto os cultos de possessão são definidos como comportamentos desviantes em relação aos valores dominantes brasileiros. Segundo, de acordo com as ideias teóricas de Douglas (1966; 1970) e Turner (1969), verificamos que ser definido pela sociedade como sujo e perigoso é frequentemente uma vantagem positiva para aqueles que exercem uma profissão ligada aos poderes mágicos (FRY, 1982, p. 56).

O autor começa seu trabalho caracterizando o candomblé e seus significados, tanto em relação a seus adeptos quanto na sua relação com a sociedade do entorno, o preconceito enfrentado pelos cultos de matriz africana, e segue com a revisão propriamente dos artigos de Ruth Landes (2002 [1947]) e Ribeiro (1969). Tais artigos, para Fry, procuram estabelecer uma conexão entre homossexualidade masculina passiva e cultos afro-brasileiros sem, entretanto, explicar os significados do que seria o homossexual passivo.

No caso de Landes, a relação que se estabelece entre homossexualidade passiva e cultos religiosos é o fato de os primeiros (os homossexuais passivos) se aproveitarem dos segundos (os cultos religiosos) para se expressarem como mulheres. Por sua vez, Ribeiro (1969) explica que a causa da homossexualidade dos seus entrevistados é: "resultado de situações conflitivas que eles experimentaram em casa com um tipo particular de família matrifocal, característica da subcultura das classes sociais mais baixas da Afro-América" (RIBEIRO, 1969 apud FRY, 1982, p.63).

A explicação de Ribeiro (1969) remete ao fato de que há uma correlação, ainda que insidiosa, entre homossexualidade e negritude, mesmo que não se desenhe como uma associação direta entre ambas, elas parecem se entrelaçar, ao menos quando se está falando em uma perspectiva negativa da homossexualidade.

Fry (1982) considera que a relação entre culto afro-brasileiro e homossexualidade masculina tem como uma de suas razões o fato de estarem, ambos, inseridos de forma "marginal" dentro da sociedade considerada "normal". Acrescentase ainda, como mais uma possibilidade, o fato de serem negros homossexuais e, portanto, considerados a "margem".

\section{Luiz Mott e a homossexualidade negra como tema central}

Em 1986, Mott publica um artigo sob o título "Escravidão e homossexualidade", no qual discute a homossexualidade negra, tendo como material empírico 


\section{hevistg all pavtg}

\} NOTAS SOBRE UM ITINERÁRIO BIBLIOGRÁFICO - MARQUES JR., J. S. \}

para a sua pesquisa os autos da Inquisição. O intento do autor foi trazer à luz a existência de práticas homossexuais entre os povos africanos desde antes da escravidão; tecer considerações sobre as relações homoeróticas estabelecidas no Brasil entre africanos e outros povos que aqui habitavam e revisar a bibliografia referente à submissão de negros escravizados ao abuso sexual.

O autor evocou a discussão freyriana, que coloca sobre o modelo escravista a responsabilidade pela suposta luxúria dos negros e, por conseguinte, dos brasileiros. Interessante perceber que, seguindo esse caminho, afirma-se que no Brasil há uma libertinagem que nos é cultural e que, de certo modo, não há limites em nossa impulsividade sexual. Para Mott (1986), esse argumento não rediscutiu essa teoria, Freyre apenas mudou o suposto "culpado da luxúria": se antes eram os negros africanos, agora seria a escravidão sobre os negros, mas os sujeitos ainda são os mesmos e permanece a ideia do irrefreável impulso sexual.

Mott (1986) discorreu sobre como se organizava a vida sexual dos escravos (principalmente os do sexo masculino), face à falta de mulheres e as formas como os fazendeiros propunham a solução para o problema: desde vários homens compartilhando a mesma mulher, até o desestímulo a relações heterossexuais.

A partir do autor, um dos possíveis resultados da escravidão teriam sido as próprias práticas homoeróticas. Seguindo esta lógica, não chega a surpreender que haja um rechaço por parte dos negros à homossexualidade, pois essa seria resultado não de uma sexualidade "normal", mas de um "desvio" causado pela escravidão. O próprio Mott menciona que:

(...) Em 1981, num debate organizado pelo Movimento Negro Unificado de Salvador, ao prestarmos a informação que, desde 1591, havia na Bahia um negro do Congo que certamente já viera sodomita de sua terra natal, fui contestado por um dos membros dessa organização, que atribui a homossexualidade na África à má influência dos colonizadores brancos (1986, p. 25).

O texto segue, porém, revelando a existência de práticas homossexuais, bem como de indícios de utilização por homens africanos de indumentária feminina, ainda na África. Tais relatos servem para balizar a proposição do autor de que a homossexualidade, de forma diversa do anteriormente apontado, não é um resultado da escravidão ou uma má influência de brancos sobre negros, mas um fenômeno existente na África antes de contatos com brancos.

Em seu último tópico, Mott (op. cit) aborda casos de sodomia relatados ao Santo Ofício para discutir as relações entre homens negros e outros homens negros ou com outros grupos raciais. Nesse momento, defende que havia relações em que o abuso, por parte de senhores brancos, era a tônica, mas que havia também relações pautadas em "livre iniciativa de ambas as partes".

O que se coloca é que, para além da ideia de uma possível prática homossexual apenas vinculada ao abuso, os negros, ainda que escravizados, tinham tal tipo de relação por prazer. A conclusão do autor é importante, pois desmistifica a 


\section{heVistg all pgutg}

\} NOTAS SOBRE UM ITINERÁRIO BIBLIOGRÁFICO - MARQUES JR., J. S. \}

ideia de uma homossexualidade atribuída aos brancos ou à escravidão como sendo a mola propulsora de tal prática entre os negros. E o artigo traz ainda a homossexualidade negra em uma perspectiva positiva, o que é algo inovador.

\section{Considerações Finais}

A partir do percurso de revisão de estudos sobre a temática, pode-se inferir que, num primeiro momento, os negros homossexuais foram estudados a partir das ideias eugenistas e higienistas, dentro dos marcos médico-criminológicos que analisaram esses sujeitos, buscando uma articulação entre homossexualidade e raça (negra), baseada nas ideias de degeneração.

Embora os autores (GREEN, 2000; FIGARI, 2007) que nos mostram os indícios dessa relação não estejam focando suas pesquisas nesses sujeitos de maneira especifica, eles nos informam a maneira como racismo e a discriminação a homossexuais estiveram, desde o período colonial, enlaçados.

Os negros (pretos e pardos) desde o inicio de sua trajetória no Brasil, foram marcados pela violência da escravidão e do preconceito que advém do estabelecimento de estereótipos. Por sua vez, o início da construção da categoria "homossexual" no Brasil é marcado pelo estereótipo e pela associação com a "marginalidade" e a "perversão". Logo, é compreensível a associação de negros e homossexuais nesse momento, pois é o traço da discriminação que marca esses sujeitos.

Em um segundo momento, é possível perceber que essa temática esteve como pano de fundo, pois, ainda que não ocupasse a centralidade da discussão, esteve presente como dado para distinção racial.

Fry (1982), ao retomar em seu artigo Landes (2002) e Ribeiro (1969), propõe uma nova forma de compreensão acerca da relação entre homossexualidade e cultos afro-brasileiros. Embora o autor não explicite a temática racial, ela aparece em face da discussão de religiões afro-brasileiras. A forma negativa como a religião é vista está diretamente associada ao fato de serem cultos de origem africana.

O autor revê a discussão acerca dos homossexuais passivos e sua relação com os cultos afro-brasileiros e, ao fazê-lo, nos oferece alguns elementos sobre a presença da homossexualidade negra nesses espaços, ainda que, como afirmado anteriormente, esse aspecto não se constitua como central para nenhum desses autores.

Em um terceiro momento, Mott (1986) centraliza a discussão na homossexualidade negra: coloca esse sujeito em um novo lugar, rediscutindo, inclusive, um possível exercício da homossexualidade em terras africanas, buscando enfatizar uma discussão positiva acerca da homossexualidade negra.

É importante perceber que, de modo geral, a bibliografia mapeada não toma como central a temática da homossexualidade negra, à exceção do artigo de Mott (1986), que problematiza essa identidade interseccional. Este é um fato que demonstra a dificuldade em dar visibilidade àqueles que partilham de uma identidade negra homossexual e sugere a necessidade de mais estudos a respeito. 


\section{hevistg all pautg}

\} NOTAS SOBRE UM ITINERÁRIO BIBLIOGRÁFICO - MARQUES JR., J. S. \}

\section{Referências bibliográficas}

BLACKWELL, M.; NABER N. Interseccionalidade em uma era de globalização: as implicações da Conferência Mundial contra o Racismo para práticas feministas transnacionais. Revista Estudos Feministas. Florianópolis: UFSC, v. 10, n.1, jan. 2002.

CAMINHA, A. O bom crioulo. Rio de Janeiro. Prefeitura da cidade do Rio de Janeiro, 1991[1894].

CARRARA, S. et al. Curso de especialização em gênero e sexualidade. Rio de Janeiro/ Distrito Federal: Secretaria de Políticas para Mulheres/CEPESC, 2010, v.3.

FANON, F. Peles negras, máscaras brancas. Rio de Janeiro: Fator, 1983.

FIGARI, C. @s outr@s cariocas: interpelações, experiências e identidades homoeróticas no Rio de Janeiro. Séculos XVII ao XX. Belo Horizonte/Rio de Janeiro: UFMG/ IUPERJ/UCAM, 2007.

FONSECA, V. O preto do arco-íris. Revista Raça Brasil. Comportamento. Disponível em: <http://racabrasil.uol.com.br/Edicoes/96/artigo15626-4.asp>. Acessado em: 25/ 02/2012.

FRY, P. Homossexualidade masculina e cultos afro-brasileiros. In: FRY, P. Para inglês ver: identidade e política na cultura brasileira. Rio de Janeiro: Zahar, 1982 [1974,1977].

FRY, P. Léonie, Pombinha, Amaro e Aleixo: prostituição, homossexualidade e raça em dois romances naturalistas. In: FRY, P. H.; EULÁLIO, A.; WALDMAN, B.; VOGT, C.; MACRAE, E.; VElHO, G.; CAMPOS, M. D.; CORRÊA, M. (Orgs.). Caminhos cruzados. São Paulo: Brasiliense, 1982, p. 33-52.

FRY, P.; MACRAE, E. O que é homossexualidade. São Paulo: Brasiliense, 1985.

GOSINE, A. "Raça", cultura, poder, sexo, desejo e amor: inscrevendo os "homens que fazem sexo com homens". In: CORNWALL, A.; JOLLY,S (Orgs.). Questões de sexualidade: ensaios transculturais. ABIA; 2008, p.167-174.

GREEN, J. N. Além do carnaval: homossexualidade masculina no Brasil do século XX. São Paulo: UNESP, 2000 [1999].

GUIMARÃES, S. A. Como trabalhar com raça em sociologia. Revista Educação e Pesquisa, São Paulo: USP, v. 29, n. 1, 2003.

LANDES, R. Matriarcado cultural e homossexualidade masculina. In: LANDES, R. A cidade das mulheres. Rio de Janeiro: UFRJ, 2002 [1947].

LIMA, A; CERQUEIRA, F. A. Identidade homossexual e negra em Alagoinhas. Bagoas: estudos gays - gêneros e sexualidades. Natal: UFRN, v. 1, p. 269-286, 2007.

MINISTÉRIO DA SAÚDE. Programa Brasil sem homofobia. Disponível em: <http:// bvsms.saude.gov.br/bvs/publicacoes/brasil_sem_homofobia.pdf.> Acesso em 28 ago. 2008.

MOTT, L. Escravidão e homossexualidade. In: VAINFAS, R. História e sexualidade no Brasil. Rio de Janeiro: Graal, 1986. 


\section{AnVistg all pgutg}

\} NOTAS SOBRE UM ITINERÁRIO BIBLIOGRÁFICO - MARQUES JR., J. S. \}

PINHO, O. A. A guerra dos mundos homossexuais: resistência e contra-hegemonias de raça e gênero. In: RIOS, L.F; ALMEIDA, V.; PARKER, R. (Org.). Homossexualidade: produção cultural, cidadania e saúde. Rio de Janeiro: ABIA, 2004.

RATTS, A. J. P. Entre personas e grupos homossexuais negros e afro-lgttb. In: BARROS JR, F.O e LIMA, S.O. (Orgs.). Homossexualidade sem fronteiras: olhares. Rio de Janeiro: Booklinks, 2007, v. 1, p. 97-118.

ROSA, W. Observando uma masculinidade subalterna: homens negros em uma "democracia racial". Trabalho apresentado no ST 18 A questão racial no Brasil e as relações de gênero O Seminário Internacional Fazendo Gênero 7: Gênero e Preconceitos, UFSC, 28,29 e 30 de agosto de 2006.

SCHWARCZ, L. K. M. O espetáculo das raças: cientistas, instituições e pensamento racial no Brasil: 1870-1930. São Paulo: Companhia das Letras, 1993.

SOUZA, R. R. As representações do homem negro e suas consequências. Revista Fórum Identidades. Sergipe: UFSE, ano 3, v. 6, p. 98-115, jul-dez. 2009.

Recebido em 24 de setembro de 2011

Aceito para publicação em 15 de dezembro de 2011 